Primary Teacher Recruitment: Careers Guidance and Advice

Mary Thornton and Ivan Reid

Dr. Mary Thornton, University of Hertfordshire

Watford Campus, Wall Hall,

Aldenham, Herts. WD2 8AT

Tel. 01707285719

email: m.e.thornton@herts.ac.uk

Professor Ivan Reid, Loughborough University, Leicester,

Leicestershire, LE11 3TU

Tel. 01509222760

email: i.reid@lboro.ac.uk

Correspondence to Dr. Mary Thornton please. 


\section{Brief Biographical Details}

Mary Thornton is a lecturer in primary education, and learning and teaching development, at the University of Hertfordshire. She has researched and written about gender, teacher education and primary teachers' careers.

Ivan Reid is Schofield Professor of Education at Loughborough University. He has researched and published widely in the fields of education and sociology. 


\title{
Primary Teacher Recruitment: Careers Guidance and
}

\section{Advice}

\begin{abstract}
The impact of careers guidance and advice on newly recruited primary teacher education students is the subject of this article. Data were obtained through questionnaire survey and follow-up interviews with new (1998 entry) primary teaching students, drawn from 14 different Higher Education institutions. The foci of the research were a wide range of issues related to recruitment into teaching, with the careers service just one amongst many potential sources of guidance and advice. However, media coverage of the research report focused primarily, and negatively, on students' views and opinions of the careers service. This article sets our findings and advice within the context of the whole research project.

(108 words)
\end{abstract}

\section{Introduction}

Media coverage of this research, part funded by the TTA (Teacher Training Agency), into 'Students’ Reasons for Choosing Primary Teaching as a Career' (Reid \& Thornton, 2000), suggested that 'School-leavers are being put off becoming primary teachers by illinformed careers advisers who fail to challenge the notion that it is a low-status, predominantly female profession'; that the research had found that 'most careers advisers gave negative advice about 
pursuing a teaching career'; that the respondents had said that 'advisers were unable to provide appropriate information about teaching'; that 'some were discouraged from considering primary teaching', by careers advisers and teachers, and that 'only $43 \%$ of 1611 student primary teachers responding to a separate questionnaire said careers advisers had been a positive influence on their decision’ (Mansell, 2000).

Data from the research that directly relate to careers guidance and advice issues are presented here in order to clarify the somewhat misleading media interpretations of the report.

\section{The research framework}

The extant literature contains no UK-wide data on primary teaching as a career choice, although Johnston et al (1998) have studied gender factors in choosing primary teaching in Northern Ireland, and were concerned that policy debate, involving recruitment and retention issues (Department for Education and Employment (DfEE) ‘Green Paper’, 1998), was based on little hard evidence.

The student sample was drawn from 14 different Higher Education institutions in England. First year under-graduates and PGCE primary students across 4 chartered and 7 non-chartered universities plus 3 university colleges were included in the survey 
which produced 1611 completed questionnaires and 148 follow-up interviews.

\section{The questionnaire}

The questionnaire used was developed from extensive face-to-face interviews with PGCE students enabling items to be devised around questions about the importance of reasons for: wanting to become a teacher; not wanting a job other than teaching; choice of primary school; not choosing to train for secondary school; options in deciding to enter their course. All questionnaires were administered during the initial part of the first term of the students' course.

\section{The interviews}

The interview schedule was designed to gain further depth to the reasoning behind the choice of important factors in respect to the reasons listed. Students were asked to explain why certain items were thought most important. In addition, the opportunity was taken to collect further data from the respondents, e.g. whether they had any reservations about primary teaching as a career; whether the teachers they had met in school while on the course had been positive about the job; what they thought might encourage, or put people off , becoming primary teachers. 
Thus the main focus of the research was students' reasons for choosing primary teaching as a career and not the specific impact careers guidance or advice had on that choice. However, data relating to the careers service and other sources of advice were collected in the final section of the questionnaire (see Table 1). This was overtly followed up during interview only where students had indicated that a particular source of advice had been important (or very important) to their career choice. Careers guidance and advice received were also mentioned by some students in their responses to other interview questions.

******** Insert Table 1 around here $* * *$

\section{Data Analysis}

Analysis of the data from the questionnaires was undertaken by the use of straightforward counts of items in respect to each question and provided a database concerning the relative importance of items in respect to face data variables - gender, age, course, institution, previous experience, subject background etc. Analysis of the interview data obtained was facilitated by the use of QRS NUD*IST (Richards \& Richards, 1997). Interview data were used to validate and / or further elucidate the statistical findings. All percentages below and in the tables are of the whole sample who completed the questionnaire (1611). 


\section{General Findings}

The positive outcomes from this research were that nine out of ten of these new students thought that the fact they enjoyed working with children was important in their choice of career. More than 95 per cent felt that teaching would bring high job satisfaction, would be a good career and would be a challenge. These are all very positive aspects of choice of teaching. Students' reasons for not wanting a job other than teaching were most clear cut. Over 99 per cent saw 'I wanted to teach' as important suggesting a high level of commitment to joining the profession.

\section{Questionnaire responses relating to careers guidance and advice.}

This section reviews the importance of factors in respect to the final question (Options in deciding to enter their course) for the whole sample, by gender, age group, type of course.

\section{The Whole Sample}

Experiential factors were the most popular group of factors identified, with 97 per cent viewing as important gaining teaching experience in school(s), 90 per cent school visits and 85 per cent taking part in out of school activities with children. Around seven out of ten identified advice from teachers, family and friends as important, with teachers being slightly more popular than the other two at 77 per cent. Advice from the careers’ service, from lecturers, 
and financial advice, were all seen as unimportant by around three in five. Perhaps surprisingly advice from the TTA, DfEE, LEAs and Unions was seen as unimportant by over seven out of ten respondents and was thus clearly the least influential factor surveyed.

\section{Gender Differences}

Gaining experience of teaching in school(s) was seen as being important by 92 per cent of men and 97 per cent of women, and the same pattern was true for visits to schools (84 and 90 per cent). Women were also more likely than men to view as important all the other factors. In particular, they viewed advice from teachers, family, friends, together with that from the careers service and the TTA/ DfEE/ LEAs/ Unions as important in larger proportions than men.

\section{Differences between age groups}

The sample was divided into mature and traditional age-entry (TAE) students with mature under-graduates defined as 21 years or older on entry to their ITE course, and mature PGCEs defined as 24 years or older on entry. TAE students were more likely to see advice from almost all sources as important than were the mature students. The comparative percentages were: advice from teachers, 81 and 70; from friends, 74 and 64; from family, 80 and 59 and from the careers service, 54 and 28. 


\section{Differences between Undergraduate and PGCE students}

Probably because of their overall younger age and that they were about to enter higher education for the first time, higher percentages of under-graduate than PGCE students saw as important every one of the listed factors in choosing their course of study. Marked differences were evident for advice from teachers (84/49), friends (73/66), family (84/57), lecturers (50/39), the careers service (57/28), the TTA/ DfEE/ LEAs/ Unions (33/22). Somewhat smaller similar differences occurred for school visits (92/85), taking part in out of school activities with children (90/80), but only marginally for gaining experience in school (98/95).

\section{Summary of relevant questionnaire data}

These observations suggest a differential impact of 'official' sources of information about primary school teaching courses, according to a number of variables. Consequently, in order to widen and/or increase recruitment, or to ensure that those who are successfully recruited have seen the 'official' information, attention should be paid to targeting those presently not reached or affected.

A summary of student responses to the importance of experience and advice factors in deciding on their course of training can be found in Table 1. It is from this table that the actual figures reported in the media emanate (Mansell, 2000). Table 1 shows 
clearly that 43 per cent of the questionnaire respondents (1611) felt that advice from the careers service had been an important (or very important) factor in their choice of primary teaching as a career. This should be seen as a positive achievement rather than 'only 43 per cent' since lecturers, TTA, DFEE, LEAs, unions and financial advisers all had far less impact on these particular students.

****** Insert Table 2 around here

It is clear, from Table 2, that experiential factors had the greatest impact on these students' reasons for choosing primary teaching as a career. This should not be surprising since real life/work experience is likely to be a stronger motivator, for or against teaching as a career, than any advice or information given by a third party, and these were students who had already been successfully recruited. One outcome of this finding was the recommendation that ideally it would seem appropriate to, 'pull' potential recruits towards teaching as a career, through work experience in schools, and to attempt to ensure that such school experiences are positive and fulfilling.

\section{Interview responses}

These data are based on records of interviews with 148 students who volunteered to be interviewed. Clearly these students were a 
self-selected group from among those successfully recruited. The findings presented here should be viewed in that context. It should also be noted that these are comments made by individual interviewees, that they are not readily quantifiable, nearly all the students' replies contain several factors and aspects and the categories are far from discrete

Students' responses to the question 'What could and should be done in order to attract more people into primary school teaching' produced three major factors (finance, the image of teaching, recruitment) and two minor ones (pressures and rewards). The following quotations have been used to display the range of students' thinking and to identify some of the ideas these contained about increasing recruitment into the profession.

\section{Finance}

The money needs to reflect the job; especially as graduates often earn more.

Pay would make a difference, for a breadwinner it is not enough.

There were clear indications of concerns about teacher's pay levels and their perceived inappropriateness for graduate entrants, attracting the more able / highly qualified, and for 'breadwinners'. Perceptions of teachers not being able to get on with the job of 
teaching, and of not being adequately financed during training (or in post) were also present.

\section{The image of teaching}

More positive press attention, especially about the benefits i.e. satisfaction.

The teaching profession needs to have a higher status in the eyes of the public - too often it is seen as a job that people do because they can't think of anything else to do.

Still seen as a ladies' job, should be more of a profession like secondary teaching. You are a professional but people do not see you as one.

While recently there have been some clear political attempts to accentuate the positive aspects of teaching and to attract positive publicity, there is clearly still much to be done. Even some of those successfully recruited reported a perceived continuation of the 'bad press' that teaching has attracted and which must clearly impact upon recruitment in general.

\section{Recruitment}

Positive introduction of the course [ITE] at A level stage.

Open days at universities using students in training to assist discussions. LEAs should offer open days in schools with informal chats to teachers and NQTs. 
Produce freely available literature outlining not only a real

teacher's 'day' but also make-up of training courses.

Workload is horrendous.....Use actual teachers of all ages and

gender to give own reasons for teaching.

More incentives for people to experience schools. If they see good

primary teachers they may want to join them.

The questionnaire responses of the successfully recruited students in the survey demonstrated the importance of the benefits they gained from positive experiences with real teachers and in the reality of teaching. The interview responses echoed this by stressing real life experience, with real teachers, as a good mechanism by which to enhance recruitment.

\section{Pressures}

It is not really just an issue of pay, it is the conditions and hours and paperwork that put people off. Maybe most of the those who it puts off would not be suited anyway, but I am sure that some fine teachers are put off ...

Funding of proper administration in schools - let teachers teach. ...remove the restrictions of the National Curriculum.

Also mentioned were more autonomy, and pupil behaviour and discipline. There were clear indications here of some perceived negative aspects of teaching which these students suggested needed 
to be addressed if recruitment was to be enhanced. Administrative and bureaucratic overload were just some among the many identified 'turn-off's'.

\section{Rewards and job satisfaction}

General awareness of what you can get out of teaching - the rewards from the children, what they give back to you. ....if they understood the buzz they could get from the children, and that no two years are the same, with no chance of getting bored....

These interview comments capture the very positive feelings [and 'pull' factors] that the successfully recruited experienced in relation to their choice of teaching as a career. It was rewarding, and challenging, and varied. A greater emphasis on the positive features of teaching, they believed, might attract more recruits.

\section{Attitudes of teachers}

Given the importance attached by the students to experience in schools, and as a strategy for bringing more people into the profession, the reception they themselves received when in school was an important consideration. In answer to the question 'Have the teachers you have met in schools while you have been on your course been positive about the job?' 54 per cent said 'yes, positive', 27 'no, negative', and 20 answered both positive and negative. However it was noticeable that answers in each category 
often contained reservations or exceptions, suggesting both a range of experiences and students’ sensitivity towards it.

\section{Positive}

They seem to have a genuine love for teaching and although they admit there can be downsides to it, they believe that if it is really what you want then it will be a great career.

\section{Negative}

No, positive about the children but not about the job, want to leave because of high pressure and low pay, lack of appreciation and support...One decided to resign...on grounds of having to do the literacy hour.

\section{Positive and negative}

Yes in terms of job satisfaction, no in relation to the constant changes, increasing amount of paperwork and bureaucracy

\section{Interview responses relating directly to careers guidance and advice}

As noted above, some students echoed the experiential factor in teacher recruitment, suggesting the need for more contact with real teachers. Just seven students, of 148, commented in interview that they had been let down by those they had sought careers advice from. 
1. It took me ages to find out the address of the TTA. Careers people knew nothing about it - so, make information more easily available - where kids go to look.

2. I think that people who express a desire to go into teaching should be properly informed and encouraged by their schools. I only succeeded by ignoring my careers advisors and teachers and relying on my stubbornness, willpower and the people at the primary school I was assisting at ...... The careers department at secondary school was useless and incorrect. There was a careers library at university but they gave me incorrect information also. The teaching profession needs to recruit and ensure the information given to teenagers is correct.

3. The careers service in the University targeted only a few areas, e.g. business, law etc. personnel. - but not PGCE for teaching.

4. People should know the options - the careers service didn't mention it. The BEd didn't seem to be seen as a degree.

5. When I was choosing my options at school I was told by careers advisers and teachers not to waste my brain on teaching.

6. Careers teachers in schools should encourage pupils more towards teaching, we were put off considering it. Need to tell them to chose the correct subjects to suit teacher training.

7. I wanted a career in teaching despite being told that it was not a stable career path to choose. 
Clearly these seven students chose teaching in spite of, rather than because of, the careers guidance and advice they received. During their interviews, they did give mainly negative reports about it. However, the number of students who did so was very small. Neither the data nor the research report supports the media claim that 'most careers advisers gave negative advice about pursuing a teaching career' (Mansell, 2000), nor could they, because the students were not asked about positive or negative careers guidance and advice but rather to rate a list of sources of advice in terms of importance to their individual career choice. In the interviews this was followed up by directly asking only about factors students had ticked as being as important / very important to them. The students' comments about the careers service were made primarily when they were asked about what could be done to aid recruitment into teaching.

It did became clear that some potential candidates for teaching may be lost through poor advice, lack of appropriate information, lack of support for teaching as a career, and indeed, in some cases actual discouragement, but these were not questions directly addressed by the research. They were incidental issues that arose from student accounts of their experiences. It was thus recommended that such issues would need to be addressed, but that they were issues for a range of bodies, not just the careers service. 
The data do however indicate that potential teacher recruits may be found by the careers service among students who are unsure about which career direction to take. It is also possible that the perceived low status of teaching as a career may impact upon some careers advisers as much as it appears to upon some potential recruits, resulting in a potential lack of support for it as a career choice through simple neglect, but that is an hypothesis not a statement of fact.

\section{Conclusions}

A major element and starting point in any consideration of recruitment strategies lies with an understanding of the current situation, an evaluation of which provides insights for development and enhancement. This research, from which negative media accounts of the careers service were derived, provided a description of a large number of those successfully recruited to ITE courses and sought to identify the importance of a range of factors in that process.

There were clear indications in the research report that there were several segments of students among those successfully recruited (differentiated by age, gender, course) and that this was likely to be true also of those who were not. It therefore concluded that further enhancement of recruitment would probably lie in identifying and addressing these segments in an appropriately and suitably 
modified format. For instance, men appeared more likely than their female counterparts to respond to 'push' factors such as salary, conditions of service and less likely to respond positively to advice and advertising.

In terms of the careers service we recommended a more pro-active stance towards teaching and the enhancement of recruitment. We stand by our recommendations but disagree strongly with the somewhat tautologous media interpretation of them i.e. that 'School-leavers are being put off becoming primary teachers by illinformed careers advisers who fail to challenge the notion that it is a low-status, predominantly female profession' (Mansell, 2000). We did not say that, nor did the students. We recognise that Careers Advisers, like teachers, are doing a difficult job in an ever changing policy environment and that it is all to easy for the media to denigrate the work of both professions through misrepresentation. We hope that this article sets the record straight. (word count main text 3259) 


\section{References.}

Department for Education and Employment, (1998). Green Paper:

Teachers Meeting the Challenge of Change, HMSO, London.

Johnston, J., McKeown, E. \& McEwen, A. (1998). Gender Factors

in Choosing Primary School Teaching, Equal Opportunities

Commission, Northern Ireland.

Mansell, W. (2000) 'Ladies' job' tag deters recruits. Times

Education Supplement. 14 th January (p.1), London.

Reid, I. \& Thornton, M. (2000). Students’ Reasons for Choosing

Primary School Teaching as a Career. Centre for Equality Issues

in Education, University of Hertfordshire, Hertfordshire.

Richards, L. \& Richards, T. (1997) QRS NUD.IST User Guide, Version 4.0, 2nd Edition, Sage, London. 
Table 1

\section{Extract from questionnaire}

How important to you were the following options in deciding to enter your course?

\begin{tabular}{l|l|l|l|l} 
& IMPORTANT & $\begin{array}{l}\text { VERY } \\
\text { IMPORTANT }\end{array}$ & $\begin{array}{l}\text { NOT } \\
\text { IMPORTANT }\end{array}$ & $\begin{array}{l}\text { NOT } \\
\text { CONSIDERED }\end{array}$ \\
\hline Gaining teaching experience in school(s) & & & & \\
\hline Taking part in out of school activities with children & & & & \\
\hline School visits & & & & \\
\hline Assessing Universities and their surrounding area & & & & \\
\hline Evaluating prospectuses & & & & \\
\hline Advice from teachers & & & & \\
\hline Advice from friends & & & & \\
\hline Advice from family & & & & \\
\hline Advice from the careers service & & & & \\
\hline Advice from: TTA, DfEE, LEA's and Unions & & & & \\
\hline Gaining financial advice & & & & \\
\hline I did not gain information/advice/experience & Yes & No & & \\
\hline
\end{tabular}
Other (please state) 
Table 2. Percentage* of students viewing factors as important influences **on their decision of course of training.

\begin{tabular}{|c|c|c|c|c|c|c|c|c|c|c|c|}
\hline \multirow[t]{2}{*}{ Influences in deciding on the chosen course of training } & \multirow{2}{*}{$\begin{array}{c}\text { Students } \\
\text { All } \\
\end{array}$} & \multicolumn{2}{|c|}{ Gender } & \multicolumn{2}{|c|}{ Age group } & \multicolumn{2}{|c|}{ Type of course } & \multicolumn{2}{|c|}{$\begin{array}{c}\text { Primary school } \\
\text { work experience }\end{array}$} & \multicolumn{2}{|c|}{$\begin{array}{c}\begin{array}{c}\text { Other work } \\
\text { experience }\end{array} \\
\end{array}$} \\
\hline & & Male & Female & Young & Mature & UG & PGCE & Yes & No & Yes & No \\
\hline & $\%$ & $\%$ & $\%$ & $\%$ & $\%$ & $\%$ & $\%$ & $\%$ & $\%$ & $\%$ & $\%$ \\
\hline Gaining teaching experience in school[s] & 97 & 92 & 97 & 98 & 95 & 98 & 95 & 98 & 73 & 96 & 97 \\
\hline Taking part in out of school activities with children & 85 & 81 & 86 & 89 & 80 & 90 & 79 & 86 & 67 & 82 & 89 \\
\hline School visits & 89 & 84 & 90 & 92 & 85 & 92 & 85 & 89 & 80 & 88 & 91 \\
\hline Assessing universities and their surrounding areas & 63 & 53 & 64 & 73 & 49 & 77 & 47 & 63 & 53 & 53 & 75 \\
\hline Evaluating prospectuses & 64 & 49 & 66 & 71 & 54 & 77 & 49 & 64 & 64 & 56 & 74 \\
\hline Advice from teachers & 77 & 70 & 77 & 81 & 70 & 83 & 69 & 77 & 70 & 72 & 82 \\
\hline Advice from friends & 70 & 65 & 70 & 73 & 64 & 73 & 65 & 70 & 72 & 66 & 74 \\
\hline Advice from family & 71 & 56 & 73 & 80 & 59 & 84 & 57 & 71 & 57 & 61 & 83 \\
\hline Advice from my lecturers & 39 & 36 & 40 & 45 & 35 & 50 & 39 & 40 & 32 & 37 & 47 \\
\hline Advice from the careers service & 43 & 31 & 45 & 54 & 28 & 57 & 28 & 44 & 37 & 32 & 57 \\
\hline Advice from: TTA, DFEE, LEAs and Unions & 28 & 20 & 29 & 31 & 23 & 33 & 22 & 28 & 24 & 24 & 32 \\
\hline Gaining financial advice & 40 & 28 & 41 & 42 & 37 & 50 & 28 & 40 & 34 & 36 & 44 \\
\hline
\end{tabular}

* \% have been rounded, $\mathrm{N}=$ 's 1611.

** both the responses 'very important' and 'important' counted as important; remaining percentage responded either 'not important' or 'not considered 
